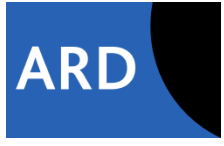

\title{
Catecholamine-producing cells in the synovial tissue during arthritis: modulation of sympathetic neurotransmitters as new therapeutic target
}

Silvia Capellino, Marco Cosentino, Christine Wolff, et al.

Ann Rheum Dis published online May 24, 2010

doi: 10.1136/ard.2009.119701

Updated information and services can be found at:

http://ard.bmj.com/content/early/2010/05/21/ard.2009.119701.full.html

\section{These include:}

References This article cites 25 articles, 10 of which can be accessed free at: http://ard.bmj.com/content/early/2010/05/21/ard.2009.119701.full.html\#ref-list-1

$\mathbf{P}<\mathbf{P} \quad$ Published online May 24, 2010 in advance of the print journal.

Email alerting Receive free email alerts when new articles cite this article. Sign up in the service box at the top right corner of the online article.

\section{Notes}

Advance online articles have been peer reviewed and accepted for publication but have not yet appeared in the paper journal (edited, typeset versions may be posted when available prior to final publication). Advance online articles are citable and establish publication priority; they are indexed by PubMed from initial publication. Citations to Advance online articles must include the digital object identifier (DOls) and date of initial publication.

To order reprints of this article go to:

http://ard.bmj.com/cgi/reprintform

To subscribe to Annals of the Rheumatic Diseases go to: 


\title{
Catecholamine-producing cells in the synovial tissue during arthritis: modulation of sympathetic neurotransmitters as new therapeutic target
}

\author{
Silvia Capellino, ${ }^{1}$ Marco Cosentino, ${ }^{2}$ Christine Wolff, ${ }^{1}$ Martin Schmidt, ${ }^{3}$ Joachim Grifka, ${ }^{4}$ \\ Rainer H Straub ${ }^{1}$
}

\begin{abstract}
- Additional data are published online only. To view these files please visit the journal online (http://ard.bmj.com) and find the article.

${ }^{1}$ Department of Internal Medicine I, Laboratory of Experimental Rheumatology and Neuroendocrino-Immunology, University Hospital, Regensburg, Germany

2Department of Clinical Medicine, Section of Experimental and Clinical Pharmacology, University of Insubria, Varese, Italy ${ }^{3}$ Institute of Biochemistry II, University Hospital, Jena, Regensburg, Germany ${ }^{4}$ Department of Orthopedic Surgery, University Hospital, Regensburg, Germany
\end{abstract}

\section{Correspondence to \\ Dr Silvia Capellino, Department of Internal Medicine I, Laboratory of Experimental Rheumatology and Neuroendocrino-Immunology, University Hospital, 93042 Regensburg, Germany; silvia.capellino@klinik.uni- regensburg.de}

Accepted 14 February 2010

\section{ABSTRACT}

Background The proinflammatory and anti-inflammatory role of the sympathetic nervous system in early and late inflammation is an unresolved paradox. A drastic loss of sympathetic nerve fibres in the synovial tissue of patients with rheumatoid arthritis (RA) has previously been demonstrated. The presence of tyrosine hydroxylase (TH)-positive cells in RA and osteoarthritis (OA) has been determined, but the role of these cells in inflammation is still unclear

Objective To characterise TH-positive cells in inflamed $\mathrm{RA}$ and $\mathrm{OA}$ synovial tissue and to study their role in inflammation.

Methods Synovial samples were obtained from 32 patients with $O A$ and 19 patients with RA and from 10 control patients. Synovial tissue samples were used for immunofluorescence staining. Synovial cells were isolated by tissue digestion and immediately used for cell culture. For in vivo experiments, collagen type-II arthritis in $\mathrm{DBA} / 1 \mathrm{~J}$ mice was induced.

Results $\mathrm{TH}+$ cells were present only in inflamed tissue and not in controls. Catecholamine-storing vesicles and vesicular monoamine transporter 2 (VMAT2) were identified in the synovial tissue. Experimental increase of cytoplasmic catecholamines by VMAT2 blockade strongly reduced tumour necrosis factor (TNF) independently of canonical extracellular $\beta$-adrenergic signalling. In addition, VMAT2 blockade increased cyclic AMP (cAMP) and cAMP responsive element binding protein, responsible for TNF inhibition. In vivo, appearance of VMAT2 positive cells was confirmed. VMAT2 blockade ameliorated inflammation also in vivo.

Conclusions This study demonstrates that local catecholamine-producing cells start to replace sympathetic nerve fibres around the onset of disease, and modulation of locally produced catecholamines has strong anti-inflammatory effects in vivo and in vitro.

\section{INTRODUCTION}

The role of the sympathetic nervous system (SNS) in causing inflammation is still not completely understood. Since the 1950s, it has been claimed that sympathetic nerve fibres aggravate inflammation-for example, in rheumatoid arthritis (RA). ${ }^{1}{ }^{2}$ Before disease onset, we confirmed the strong proinflammatory influence of the SNS in inflammation. ${ }^{34}$ Surprisingly, in the chronic phase of arthritis, the SNS has a strong anti-inflammatory role as substantiated by chemical SNS blockade. ${ }^{3}$ Very similar effects of SNS were recently described in two models of chronic inflammatory bowel disease. ${ }^{5}$ The mechanisms behind the transition from proinflammatory to anti-inflammatory effects are elusive, but we were convinced that they might explain the dual role of SNS in inflammatory diseases.

Nowadays, it is well documented that sympathetic neurotransmitters directly influence immune cells via adrenergic receptors (reviewed by Kin and Sanders ${ }^{6}$ ). Effects of catecholamines on different cell types depend on distinct receptor subtypes with opposing signalling pathways (summarised by Watling and Miller et al ${ }^{78}$ ). Stimulation of $\alpha 2$-adrenoceptors ( $\alpha 2 \mathrm{ARs}$ ) decreases cyclic AMP and stimulates tumour necrosis factor (TNF), whereas binding of $\beta A R$ s leads to cyclic AMP stimulation and downregulation of TNF. ${ }^{10}$ In contrast to sympathetic nerve fibres, the vagus nerve always has an important anti-inflammatory role in arthritis, as well described. ${ }^{11} 12$ Since norepinephrine (NE) demonstrates markedly higher affinity for $\alpha A R s$ than $\beta$ ARs, low levels of NE preferentially stimulate $\alpha$ ARs. These proinflammatory $\alpha$-adrenergic effects also stimulate pain pathways. ${ }^{13}$ Under consideration of the rapid loss of sympathetic nerve fibres in inflamed tissue, ${ }^{35} 8$ we and others explained the proinflammatory influence of the SNS by low catecholamine concentrations and $\alpha A R$ involvement. ${ }^{13} 14$ However, this does not explain the observed anti-inflammatory effect of the SNS in the late phase of arthritis when sympathetic nerve fibres are completely lost and remaining neurotransmitter concentration in the tissue is low. ${ }^{3}$

In recent years, it became clear that both sympathetic nerve fibres and immune cells produce catecholamines in the periphery. ${ }^{15-18} \mathrm{We}$ also identified cells positive for tyrosine hydroxylase (TH), the key enzyme for catecholamine production, only in synovial tissue of patients with chronic inflammation. ${ }^{8} 19$ The loss of sympathetic nerve fibres and the increase of $\mathrm{TH}+$ cells positively correlated with the inflammation index and with the amount of interleukin 6 and interleukin 8 released from inflamed tissue. ${ }^{819}$ Catecholamine-producing cells can influence inflammation as recently shown in acute inflammatory lung injury. ${ }^{18}$

The aims of this study were to characterise TH+ cells present in the synovial tissue, to demonstrate the role of local catecholamine production during arthritis and to define the cellular pathway involved.

\section{PATIENTS AND METHODS}

\section{Patients and control subjects}

Nineteen patients with RA and 32 patients with osteoarthritis (OA) who underwent knee joint 
replacement surgery were included without further selection (table 1 online supplementary file). Control synovial tissue samples were obtained from patients with joint trauma during routine arthroscopy or open joint surgery for diagnostic and therapeutic procedures (mean age $41 \pm 5$ ). All patients were informed of the purpose of the study and gave written consent. The study was approved by the ethical committee of the University of Regensburg.

\section{Synovial tissue preparation and cell culture}

The tissue preparation for histological studies was performed as previously described. ${ }^{8}$

For in vitro cell culture experiments, mixed synovial cells ${ }^{20}$ (online supplementary figure 1) were isolated by enzymatic tissue digestion as previously described. ${ }^{8}$ Cells were cultured with different substances for $24 \mathrm{~h}$, and then supernatants were collected and frozen until needed for cytokine and catecholamine determination. For more details, see online supplementary file.

\section{Superfusion technique of synovial tissue}

As described previously in detail for spleen slices, ${ }^{21}{ }^{22}$ we used a superfusion chamber $(80 \mu \mathrm{l})$ apparatus to superfuse pieces of $\mathrm{OA}$ and RA synovial tissue with culture medium. At $120 \mathrm{~min}$, superfusate was collected in order to measure spontaneous catecholamine release (see below). The superfusate was collected in tubes prefilled with ethylenebis(oxyethylenenitrilo)tetra-acetic acid/glutathione (EGTA/GSH) solution (final concentration $37 \mathrm{mM}$ EGTA and $30 \mathrm{mM} \mathrm{GSH}$ ) and immediately frozen.

\section{Blood cell isolation}

Blood samples of patients with $\mathrm{OA}$ and RA were centrifuged to remove plasma. The erythrocytes were lysed with specific lysis buffer (Qiagen, Hilden, Germany). Isolated blood cells were counted and spotted on glass slides at the concentration of 10.000 cells/spot using the Cytospin (Cytospin3, Shandon, Frankfurt, Germany). Samples were then fixed with 3.7\% formaldehyde for $20 \mathrm{~min}$ and stored at $-20^{\circ} \mathrm{C}$ until use.

\section{Immunofluorescence staining of synovial tissue and isolated cells}

Cryosections $(8 \mu \mathrm{m})$ of at least three different formaldehydefixed synovial tissue samples from each patient were used. Cultured cells (U937 and THP-1) were spotted on a glass slide and fixed, as described above for blood cells.

Non-specific binding sites were blocked with phosphate-buffered saline containing 10\% fetal bovine serum, $10 \%$ bovine serum albumin and $10 \%$ normal chicken serum for $45 \mathrm{~min}$ at room temperature. The samples were then incubated with the respective primary antibody (or with both primary antibodies, for double staining) for $3 \mathrm{~h}$ at room temperature, washed and then incubated with specific secondary antibody for $90 \mathrm{~min}$. After 4'-6-diamidino-2-phenylindole staining (Roche, Mannheim, Germany), slides were covered with fluorescence mounting medium (DAKO, Hamburg, Germany) and stored at $+4^{\circ} \mathrm{C}$ until microscopy (performed within 4 days). Control staining with the secondary antibody alone and with respective isotype controls were carried out in parallel and showed no positive staining (supplementary figure 2). For more details see online supplementary table 2.

\section{Evaluation of positive cells and nerve fibre density}

The density of positive cells and positive nerve fibres was averaged from 17 randomly selected high-power fields at a magnification of $400 \times$ and expressed per square millimetre.

\section{High performance liquid chromatography}

Catecholamines in the cells and in the culture medium were assayed by high performance liquid chromatography with multi-electrode electrochemical detection, as described previously. ${ }^{23}$ The chromatograms were collected, stored and processed with the application software Coularray for Windows (ESA). Catecholamines were quantified using the peak heights of a standard curve generated by injecting known samples ( 3 fmol to 3 pmol), and values were finally normalised for cell number. Using this method, the detection limit for catecholamines and metabolites was $0.10 \times 10^{-12} \mathrm{~mol} / \mathrm{ml}$.

\section{TNF measurement}

Quantification of TNF was performed using Beadlyte cytokine assay (Upstate) according to the manufacturer's protocol by Luminex Oosterhout, The Netherlands; (Luminex 100, Software: IS2.2). This method allows a sensitive cytokine determination even in very small sample volume $(<50 \mu \mathrm{l})$. Cytokine determination in each sample was performed in duplicate.

\section{Cell culture of U937 and THP-1}

U937 and THP-1 human monocytic cell lines were used as control for TNF and catecholamine quantification. U937 cells were also used for intracellular TNF measurement and TNF mRNA evaluation. For more details, see online supplementary file.

\section{RNA isolation and real-time PCR}

cDNA was converted from $1 \mu \mathrm{g}$ of total RNA (Invitrogen RT Kit; Invitrogen, Groningen, The Netherlands). For quantitative PCR (qPCR), $2 \mu$ l of cDNA preparation, $2 \mu$ l of Primer Assay specific for human TNF (Quiagen) or $1 \mu \mathrm{l}$ primers for $\beta$-actin (Sigma Aldrich, Deisenhofen, Germany) and SybrGreen PCR master mix (Quiagen) were applied in a total volume of $20 \mu 1$. The PCR primers and programme used are described in the supplementary file.

The PCR reaction was evaluated by melting curve analysis according to the manufacturer's instructions (LightCycler technology; Roche). Each qPCR was performed at least in duplicate for two sets of RNA preparations.

\section{Animals and arthritis model}

For in vivo experiments, collagen type-II arthritis was induced in DBA/1J mice. One hind paw was injected with $600 \mu \mathrm{g}$ reserpine or with dimethylsulphoxide (control) (day 0) when swelling reached a score 8 of 12 . The swelling score of all paws was evaluated daily until day 14 after the first injection. Scoring was performed in a blinded manner. For more details about the procedure, see supplementary file.

\section{Evaluation of the presence of vesicular monoamine transporter 2+ (VMAT2 +) cells in inflamed paws}

For the evaluation of VMAT2 + cells in inflamed paws, mice were killed at day 0 (first collagen type-II immunisation) and at days 28 and 60 after the first immunisation. Paws were fixed for 24 $\mathrm{h}$ with $3.7 \%$ formaldehyde and then decalcified in RDO (Apex Engineering, Aurora, Illinois, USA) for $36 \mathrm{~h}$. Thereafter, they were embedded in TissueTek (Sakura Finetek, Alphen aan den Rijn, The Netherlands), and quick frozen floating on liquid nitrogen. All samples were stored at $-80^{\circ} \mathrm{C}$. Immunofluorescence staining was performed as described above.

\section{Statistical analysis}

Two groups were compared by the non-parametric MannWhitney $U$ test (SPSS). The effect of treatment over time in 
animal experiments in vivo (figure $5 \mathrm{D}, \mathrm{E}$ ) was tested using the General Linear Model analysis (GLM, SPSS, version 16.0). A p value of $\leq 0.05$ was considered significant.

\section{RESULTS}

Nerve fibre density and presence of catecholamine-producing cells in inflamed tissue

The density of sympathetic TH+ nerve fibres was drastically reduced in patients with RA compared with trauma controls and patients with $\mathrm{OA}$ (figure $1 \mathrm{~A}$ ).

Despite a smaller number of sympathetic nerve fibres in RA synovial tissue, the amount of NE released from the tissue was similar between $\mathrm{OA}$ and RA but the concentration was low (only $\alpha$-adrenergic effects expected) (figure 1B). By performing TH staining of nerve fibres, we found numerous cells positive for this enzyme (figure 1C). Importantly, no $\mathrm{TH}+$ cells were found in trauma scontrols. The density of $\mathrm{TH}+$ cells was higher in RA than in OA (figure 1C). This may explain the similar release of NE from RA and OA tissue (figure $1 \mathrm{~B}$ ). Since $\mathrm{TH}+$ cells might enter the tissue after circulation in the blood, the presence of $\mathrm{TH}+$ cells in blood was tested in the same patients. The number of TH+ cells detectable in the blood was small and similar in trauma controls, $\mathrm{RA}$ and $\mathrm{OA}$ (figure 1D).
A

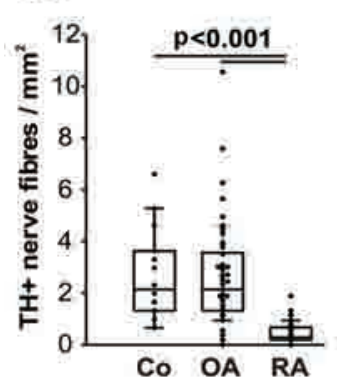

D

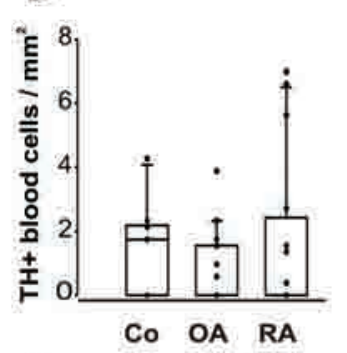

I

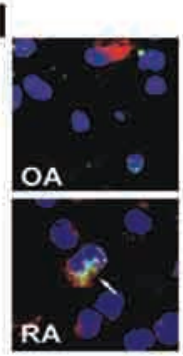

M

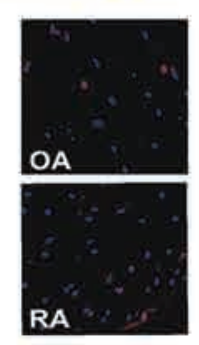

B

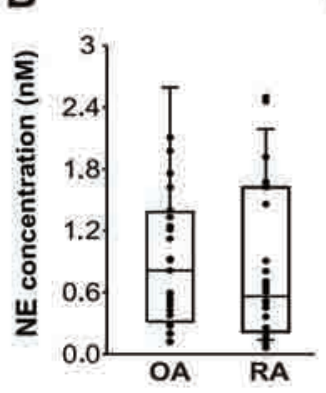

E

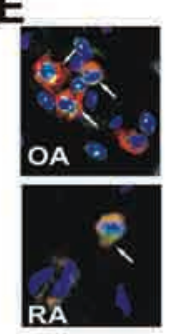

F
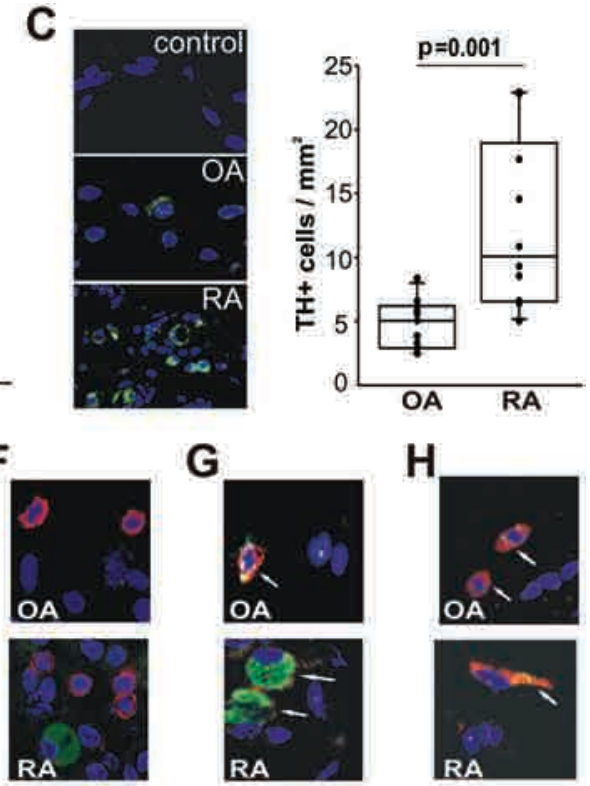

G

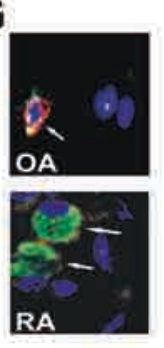

H
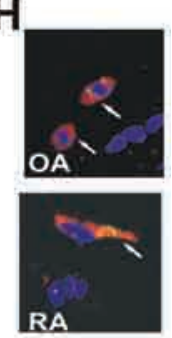

L
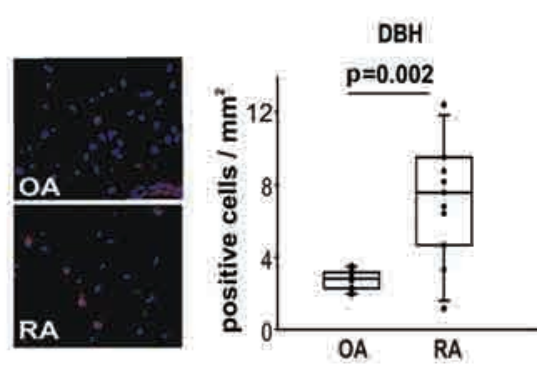

N
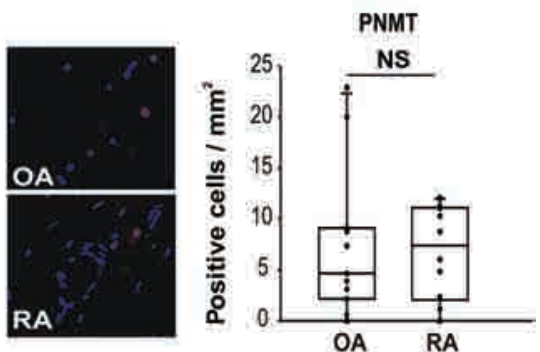

Figure 1 Characterisation of tyrosine hydroxylase (TH)-positive synovial cells in patient material. (A) Sympathetic nerve fibre density in synovial tissue of control subjects ( $\mathrm{Co}_{0}$, after trauma surgery), osteoarthritis (OA) and rheumatoid arthritis (RA) synovial tissue. (B) Concentration of norepinephrine in superfusate of $\mathrm{OA}$ and RA synovial tissue. (C) Density of TH+ cells in synovial tissue. Left panel: immunofluorescence staining. No $\mathrm{TH}+$ cells were found in control subjects; right panel: quantification of TH+ cell density in OA and RA. (D) TH+ cells in the blood. (E-K) Immunofluorescence double staining of TH (green) and different markers of synovial/immune cells (red). CD163 in E, CD3 in F, CD19 in G, prolyl-4hydroxylase in $\mathrm{H}$, elastase in $\mathrm{I}$, tryptase in $\mathrm{J}$ and vesicular monoamine transporter 2 (VMAT2) in $\mathrm{K}$. Arrows indicate double-positive cells (yellow colour). (L-N) Density of synovial cells positive for dopamine- $\beta$-hydroxylase (DBH) (in panel L), DOPA decarboxylase (in panel M) and phenylethanolamine-N-methyl-transferase (PNMT) (in panel N). Left panel: red immunofluorescence staining; right panel: quantification of cell density in OA and RA synovial tissue. NS, non-significant. 


\section{Characterisation of $\mathrm{TH}+$ cells}

In $\mathrm{OA}$ and RA synovial tissue, we found double staining of $\mathrm{TH}$ togetherwith CD163+ (macrophages), CD19+ (B cells), or prolyl4-hydroxylase (fibroblasts), but CD3+ T cells were not positive for $\mathrm{TH}$ (figure $1 \mathrm{E}-\mathrm{H}$ ). In patients with RA only, we found some mast cells and neutrophils positive for TH (figure 1I, J). TH+ cells were also positive for VMAT2, which is indicative of catecholamine storage in intracellular vesicles (figure $1 \mathrm{~K}$ ).

In order to demonstrate that $\mathrm{TH}+$ cells enable catecholamine generation, we performed immunofluorescence staining for other enzymes involved in catecholamine synthesis. The number of cells positive for dopamine- $\beta$-hydroxylase $(\mathrm{DBH})$ and 3,4dihydroxyphenylalanine (DOPA) decarboxylase were higher in RA than in OA (figure 1L, M), whereas the density of phenylethanolamine-N-methyltransferase+ cells was similar in the two groups (figure $1 \mathrm{~N}$ ). The number of cells positive for $\mathrm{DBH}$ and DOPA-decarboxylase was similar to the number of $\mathrm{TH}+$ cells (figure $1 \mathrm{~L}, \mathrm{M}$ versus figure $1 \mathrm{C}$ ).

\section{Locally produced catecholamines have very little extracellular effects on TNF secretion}

After $24 \mathrm{~h}$ of culture, catecholamines were present in supernatants of isolated synovial cells. There was no difference in levels of dopamine, NE and epinephrine release between OA and RA cell cultures (figure $2 \mathrm{~A}-\mathrm{C}$ ). As further demonstration that $\mathrm{TH}+$ cells really produce catecholamines, we incubated synovial cells with labelled $\left[{ }^{14} \mathrm{C}\right] \mathrm{L}$-tyrosine and detected the presence of labelled catecholamine metabolite homovanillic acid in cell lysates after $24 \mathrm{~h}$ of culture (for more details, see supplementary file).

In further analyses, the presence and function of adrenergic receptors was investigated. In OA and RA synovial tissue, the number of $\alpha 1$ AR-positive cells did not differ between the two groups, but the density of positive cells tended to be higher in patients with RA (figure 2D). Blockade of $\alpha 1$ ARs with benoxathian induced a slight reduction of TNF secretion in OA but not in more inflamed cells of patients with RA (figure $2 \mathrm{E}$ ). No differences were detected for the density of $\alpha 2 A R+$ cells in $O A$ and RA (figure $2 F$ ). Blockade of $\alpha 2 A R s$ did not alter TNF secretion (figure $2 \mathrm{G}$ ). For $\beta 2 \mathrm{ARs}$, no differences were found for the density of positive cells in patients with $O A$ and RA, although the number of $\beta 2 A R$ cells tended to be lower in patients with RA (figure $2 \mathrm{H}$ ). Blockade of $\beta$ ARs with nadolol did not alter TNF secretion (figure 2I).

\section{An increase of cytoplasmic catecholamines strongly inhibits TNF secretion}

The density of VMAT2+ cells was five times higher in RA than in OA (figure 3A). However, the density of catechol-Omethyltransferase $+(\mathrm{COMT}+)$ cells was similar in the two groups (figure $3 \mathrm{~B}$ ).

Binding of VMAT2 by reserpine avoids catecholamine storage in vesicles and increases cytoplasmic catecholamine levels for a few hours (one-shot effect). ${ }^{24}$ After treatment with reserpine, we observed a strong dose-dependent inhibition of TNF secretion, both, in OA and RA cells (figure 3C). Similar dosedependent TNF-inhibiting effects were obtained by treating cells with the COMT inhibitor OR486 (figure 3D). In combination experiments with reserpine and OR486, a still stronger inhibition of TNF secretion, even at the lowest concentration of reserpine, was observed (figure $3 \mathrm{E}$ ).

In further experiments, the site of action of catecholamines was tested. Synovial cells were treated with reserpine and OR486 in combination with the hydrophilic $\beta A R$ antagonist nadolol, which does not pass the cell membrane. Reserpine effects on TNF were not altered in the presence of nadolol (figure 3F), demonstrating that catecholamines released from vesicles do not act extracellularly through canonical $\beta 2$ ARs.

\section{Mechanism of action of cytoplasmic catecholamines}

Since it is difficult to get large numbers of primary cells from patients with RA and OA, we performed further experiments with the human monocytic cell lines U937. After stimulation with phorbol myristate acetate and lipopolysaccharide, U937 expressed TH and VMAT2 (figure 4A, B), and they produced catecholamines in a similar concentration range like primary cells (data not shown). Moreover, reserpine inhibited TNF secretion in stimulated U937 cells similarly as in primary cells (figure 4C).

To investigate whether TNF inhibition was due to catecholamine release into the cytoplasm and not to an unspecific effect of reserpine, the human monocytic cell line THP-1 was tested. In contrast to U937, this cell line was negative for $\mathrm{TH}$ and VMAT2 (figure 4D, E). However, THP-1 cells produced TNF after stimulation with lipopolysaccharide (figure 4F). Reserpine treatment of stimulated THP-1 did not alter TNF secretion into supernatants (figure 4F). These results demonstrate that reserpine specifically inhibits TNF by catecholamine-dependent effects.

The strong decrease of TNF in the supernatants after reserpine treatment might be due to cytoplasmic accumulation of TNF. This was ruled out since the TNF level in U937 cell lysates was lower after reserpine treatment than in controls (figure 4G). In addition, reserpine treatment decreased TNF mRNA after $24 \mathrm{~h}$ compared with controls (figure $4 \mathrm{H}$ ).

\section{Effects of cytoplasmic increase of catecholamine on inflammation in vivo}

Owing to the strong effects of reserpine on TNF secretion in vitro, we wanted to test if manipulation of cytoplasmic catecholamines is effective in vivo. Collagen type-II arthritis was induced in DBA/1J mice. In arthritic animals, as shown in figure 5A-C, VMAT2+ cells appear in the joints of DBA/1J arthritic mice. These cells are absent at the time of immunisation (figure $5 \mathrm{~A}$ ) but are detectable 28 days after immunisation at disease onset (figure 5B). Importantly, the number of VMAT2+ cells in joints greatly increased 60 days after immunisation in the chronic phase of arthritis (figure 5C).

The local treatment with reserpine ameliorated the clinical score compared with control mice (figure 5D), This positive effect already appeared 3 days after the first injection of reserpine, and the beneficial effect was stable until day 14 after the first injection (figure 5D). Importantly, reserpine only demonstrated local effects because there was no influence on untreated paws (figure 5E).

\section{DISCUSSION}

This study demonstrates the presence of catecholamine-producing cells in the synovial tissue during arthritis. These cells are not present in control tissue, suggesting that they are related to chronic inflammation. Catecholamine-producing peripheral blood cells were described earlier. ${ }^{15} 161823$ They also appear in the peripheral blood of patients with multiple sclerosis, ${ }^{25}$ and these cells can change catecholamine production depending on disease activity. ${ }^{26}$ In patients with RA, who markedly lose sympathetic nerve fibres, the density of catecholamineproducing cells was higher than in patients with $\mathrm{OA}$, who do 


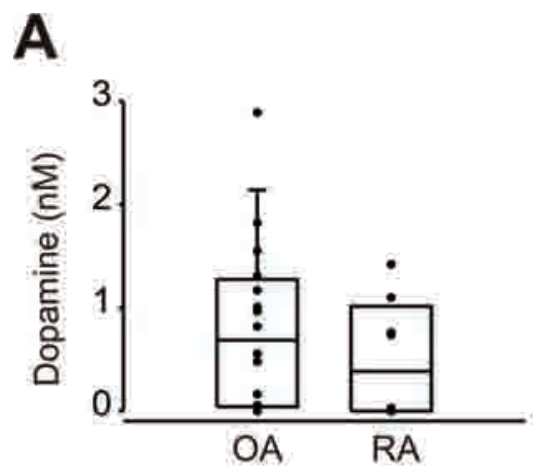

B

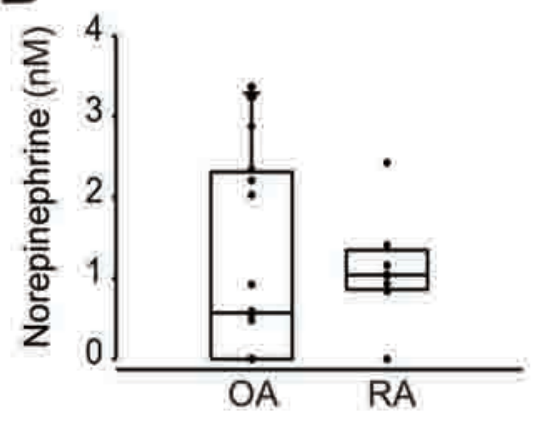

C

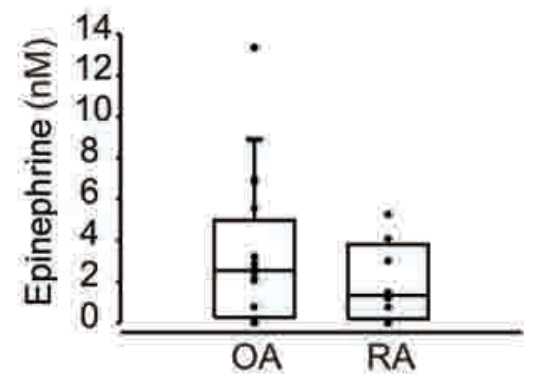

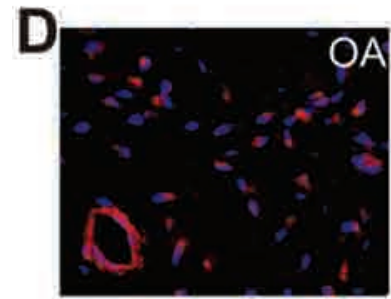
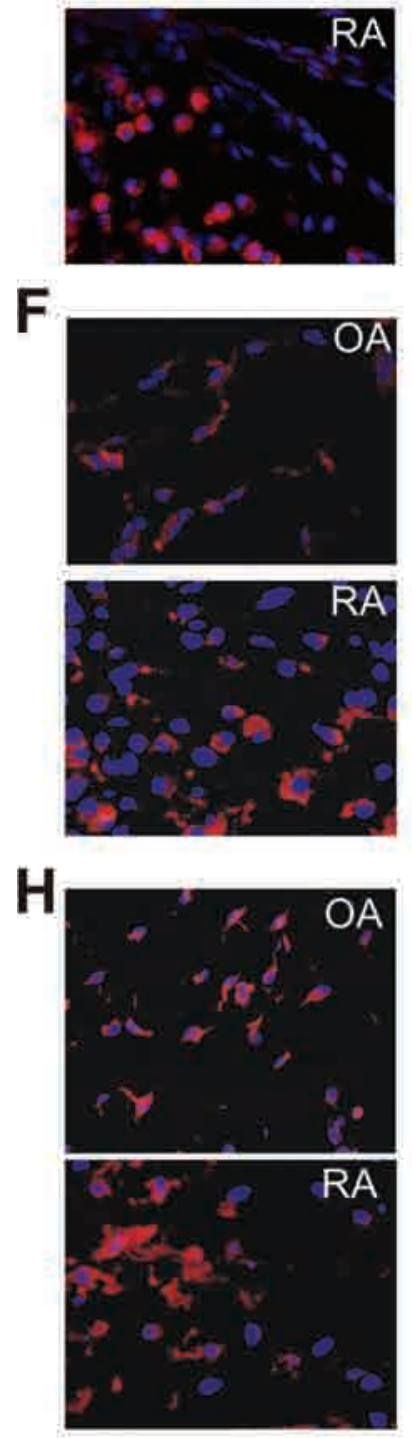

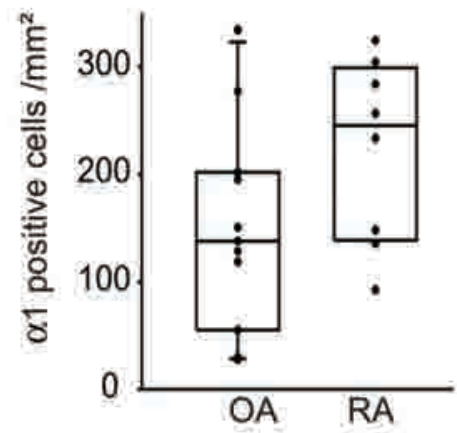

E

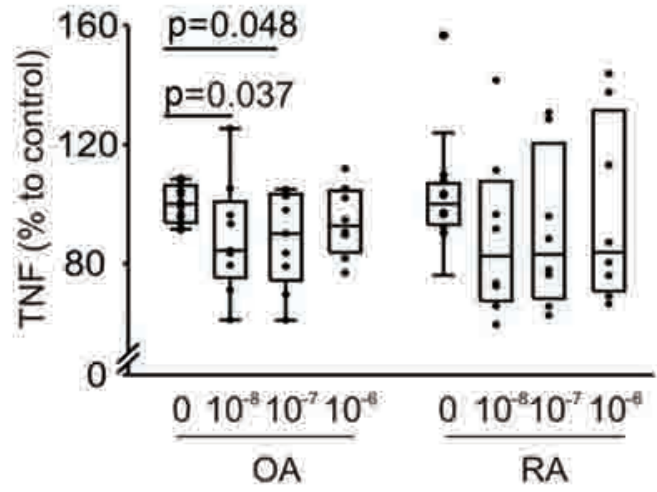

G

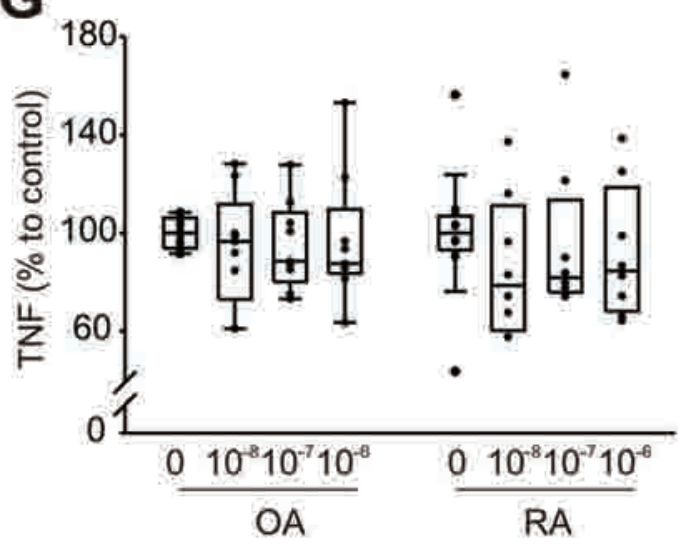

I

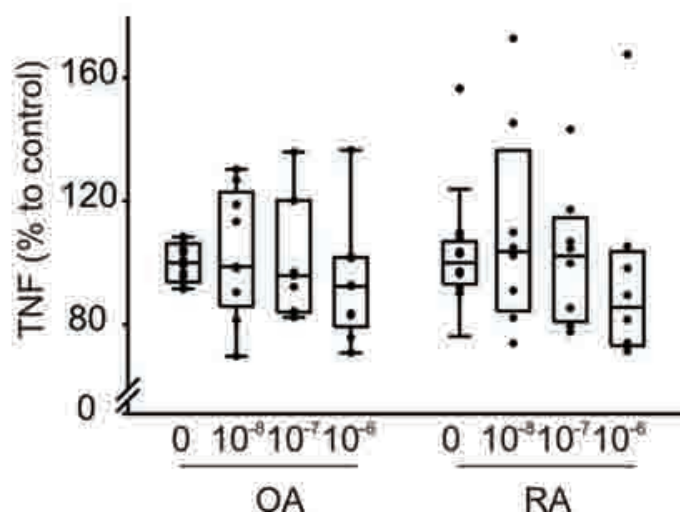

Figure 2 Extracellular effects of locally produced catecholamines. (A-C) Quantification of dopamine (in panel A), norepinephrine (in panel B) and epinephrine (in panel $\mathrm{C}$ ) released by isolated synovial cells after $24 \mathrm{~h}$ of cell culture. (D, F, H) Density of $\alpha 1$-adrenoceptor $(\alpha 1 \mathrm{AR})(\mathrm{D}), \alpha 2 \mathrm{AR}(\mathrm{F})$ and $\beta 2 A R(H)$. Positive cells in synovial tissue from patients with osteoarthritis $(O A)$ and RA. Left panel: immunofluorescence staining; right panel: quantification of positive synovial cells. (E) Tumour necrosis factor (TNF) secretion after blockade of $\alpha 1$ AR by benoxathian. (G) TNF secretion after blockade of $\alpha 2 A R$ by yohimbine. (I) TNF secretion after blockade of $\beta 2 A R$ by nadolol. 

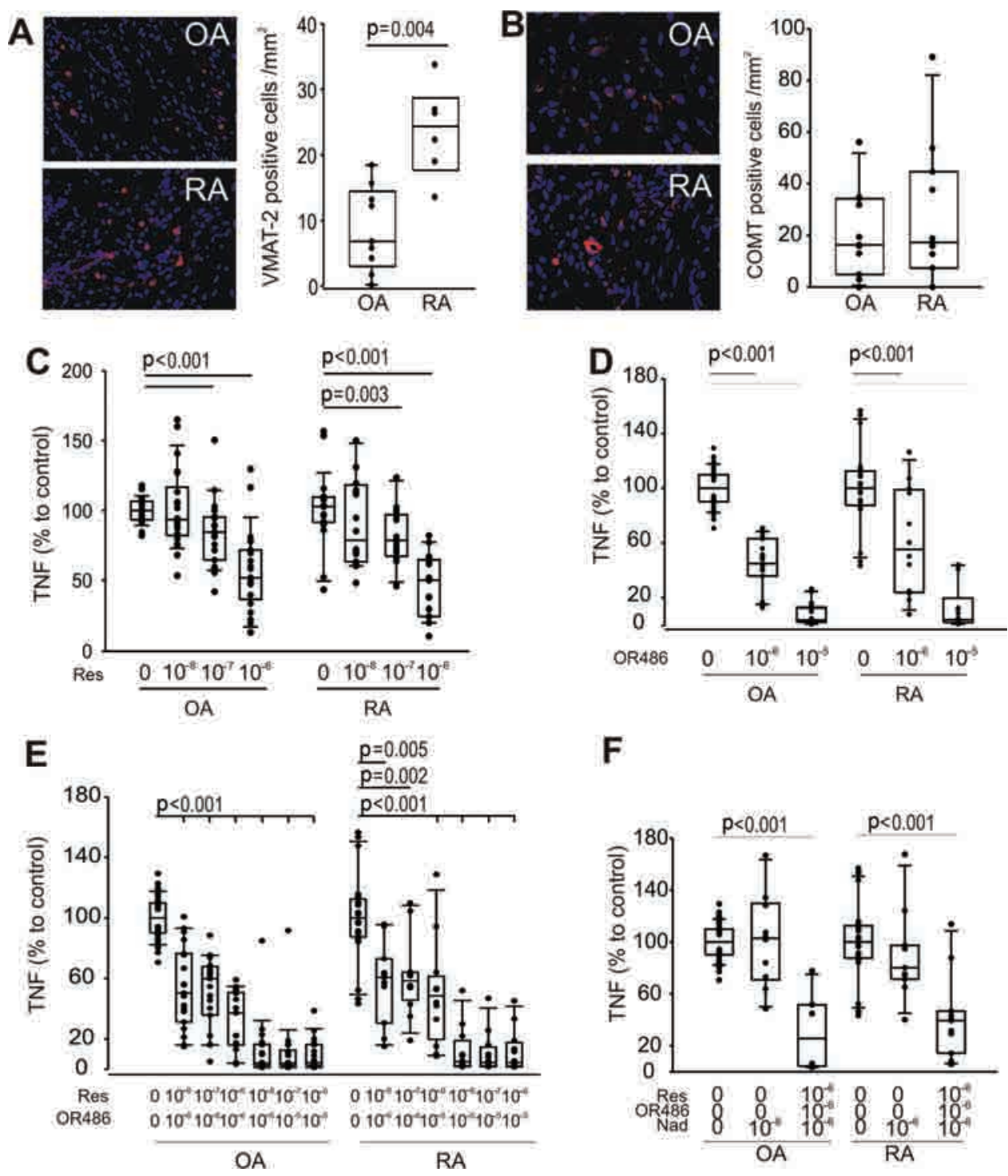

Figure 3 Effects of locally produced catecholamines after reserpine treatment. (A, B) Presence of vesicular monoamine transporter 2 (VMAT2) (A) and catechol-0-methyltransferase (COMT) (B) positive cells in osteoarthritis/rheumatoid arthritis (OA/RA) synovial tissue. Left panel: immunofluorescence staining; right panel: quantification of positive synovial cells. (C) Tumour necrosis factor (TNF) secretion after blockade of VMAT2 by reserpine (Res). (D) TNF secretion after $24 \mathrm{~h}$ of COMT inhibition with different concentrations of OR486. (E) Combined treatment with reserpine and OR486. (F) Combined treatment with reserpine, OR486 and nadolol (Nad).

not lose sympathetic innervation. Of interest, different cells in OA and RA synovial tissue can produce catecholaminesfibroblasts, macrophages, B cells, mast cells and granulocytes. It seems that many different cells switch-on the catecholamineproducing machinery in a coordinated fashion when inflammation starts and sympathetic nerve fibres get lost. As TH+ cells were not increased in OA and RA blood samples, we believe that cells switch-on catecholamine production only locally in the inflamed area.

In order to understand the role of locally produced catecholamines on inflammation, we analysed the effects of AR blockade on cytokine release. Although $\alpha$ ARs and $\beta$ ARs are present in the synovial tissue, blockade with specific antagonists did not strongly alter cytokine release, suggesting that locally produced catecholamines act intracellularly or via non-canonical pathways. Blockade of catecholamine storage into vesicles by reserpine caused a very strong and specific inhibition of TNF
mRNA and TNF protein from cells of patients with OA and RA, which was independent of canonical extracellular $\beta A R$. TNF inhibition after reserpine was even stronger when catecholamine degradation by COMT was blocked. Experiments performed using two different human cell lines demonstrated that reserpine effects are due to intracellular catecholamine release and are not an unspecific effect of reserpine on TNF.

These positive effects of the cytoplasmic catecholamine increase prompted us to test the principle in vivo. It was found that local treatment with reserpine markedly reduced inflammation without causing systemic side effects in the animals. As reserpine has a longlasting effect in vivo, only two injections were necessary to obtain strong anti-inflammatory effects. As cells start producing catecholamines after onset of disease, we infer that the proinflammatory effect of late sympathectomy already described ${ }^{3}$ is due to chemical destruction of catecholamine-producing cells. 

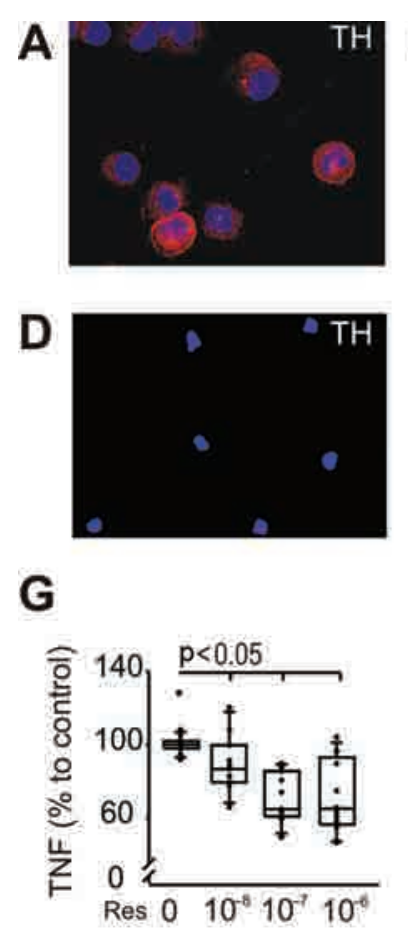
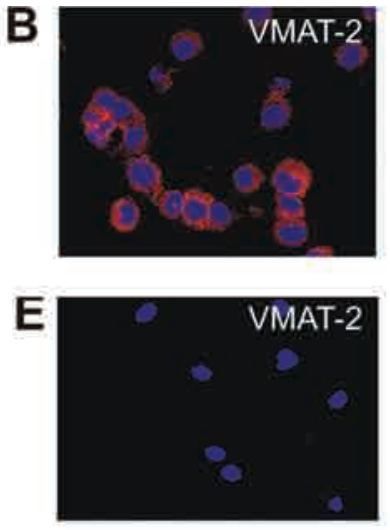

H

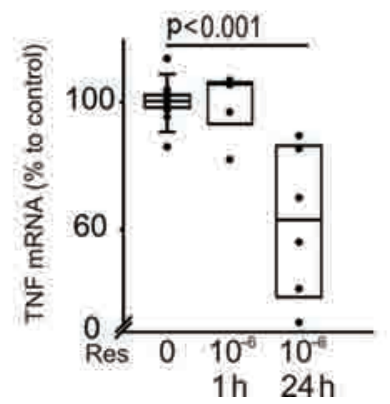

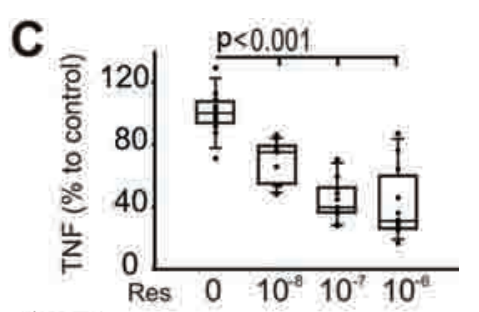

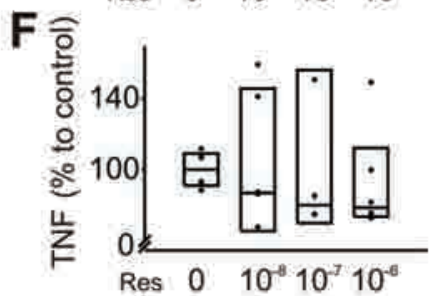

Figure 4 Influence of increased cytoplasmic catecholamines. (A-B) Immunofluorescence of U937 cells after phorbol myristate acetate and lipopolysaccharide (LPS) stimulation. (A) Tyrosine hydroxylase (TH) staining; (B) vesicular monoamine transporter 2 (VMAT2) staining; (C) $24 \mathrm{~h}$ Reserpine treatment of U937 cells $(n=10)$. (D,E) Immunofluorescence of THP-1 cells after LPS stimulation. (D) TH staining; (E) VMAT2 staining; (F) 24 h Reserpine treatment of THP-1 cells $(n=6)$. (G) Intracellular tumour necrosis factor (TNF) measured in U937 cells after $24 \mathrm{~h}$ of reserpine treatment $(n=10)$. (H) TNF mRNA content after $1 \mathrm{~h}$ or $24 \mathrm{~h}$ of reserpine treatment, measured by quantitative PCR $(n=6)$. Control box plot represents mRNA values of untreated cells after $1 \mathrm{~h}$ and $24 \mathrm{~h}$.
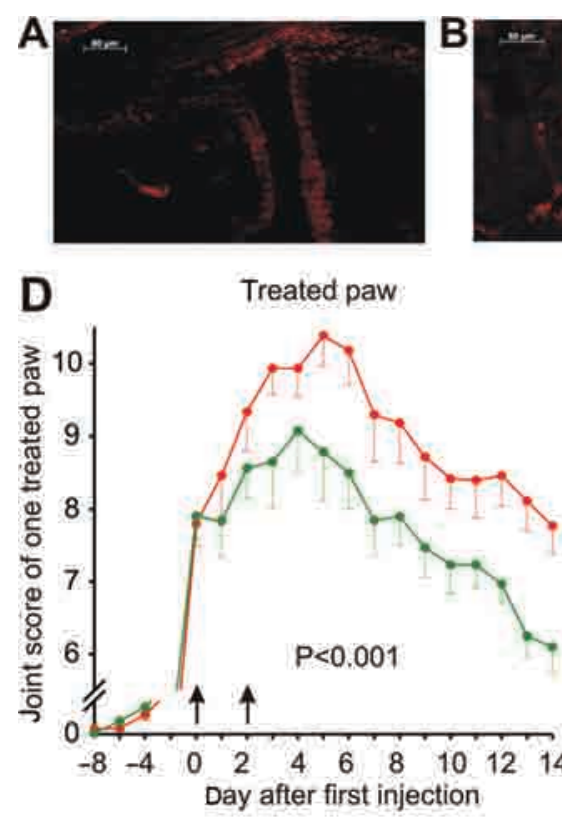
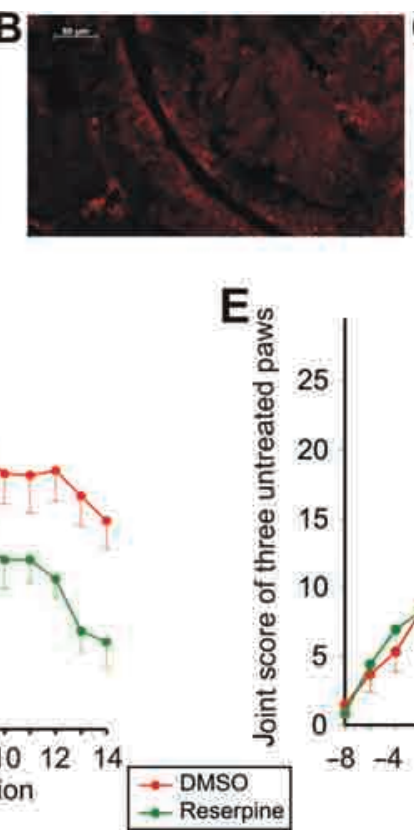

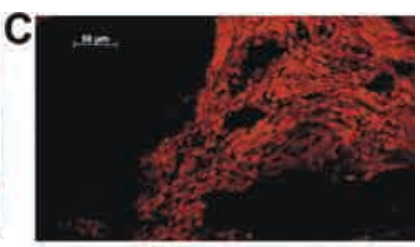

Untreated paws

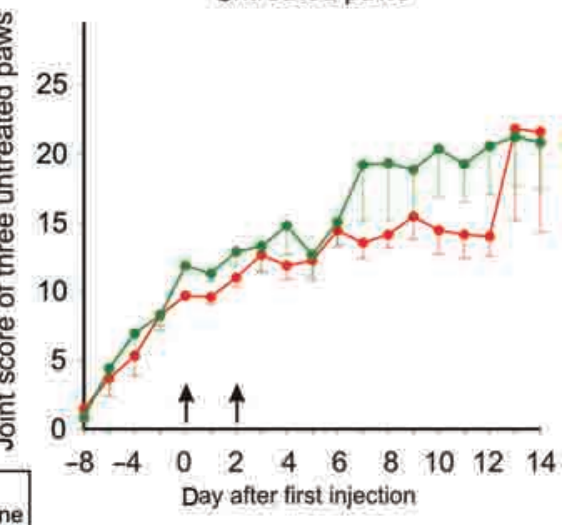

Figure 5 Effects of cytoplasmic increase of catecholamine on inflammation in vivo. (A-C) Immunofluorescence staining of vesicular monoamine transporter 2 (VMAT2) in immunised DBA/1J mice at different time points in relation to immunisation. (A) Day of immunisation. (B) Day 28 after immunisation. (C) Day 60 after immunisation demonstrates many VMAT2 + cells in inflamed tissue. (D) Evaluation of joint swelling in one hind paw after treatment with reserpine (Res; green line) or dimethylsulphoxide (DMSO; control, red line). Arrows indicate injection days. Statistical analysis (general linear model) showed a significant difference between the two curves $(p<0.001)$. Day 0 is the day on which score 8 was reached. (E) Evaluation of joint swelling in untreated paws. The sum score of the three untreated extremities was calculated in every mouse (arrows indicate injection days of treated paw, see (F)). 
In conclusion, this study demonstrates for the first time that peripheral cells start producing catecholamines during chronic inflammation, and the increase of cytoplasmic catecholamines has strong anti-inflammatory effects in vitro and in vivo. Therefore, modulation of catecholamine-producing cells could be used as a new therapeutic target in arthritis.

Acknowledgements The authors are grateful to Raffaella Bombelli, Kristina Weber, Angelika Gräber and Margit Nützel for helpful assistance in cell culture and in vivo experiments. The authors thank Dr Marienhagen for his help through injection of 3-iodobenzylguanidine in the Department of Nuclear Medicine of the University Hospital Regensburg.

Funding This study was funded by the Deutsche Forschungsgemeinschaft (German Research Society) (DFG FOR696, STR 511/14-1, 2).

Competing interests None.

Patient consent Obtained.

Ethics approval This study was conducted with the approval of the ethical committee of the University of Regensburg.

Provenance and peer review Not commissioned; externally peer reviewed.

\section{REFERENCES}

1. Fellinger K, Schmid J, Leonhartsberger F, et al. Sympathetic block in primary chronic polyarthritis. Munch Med Wochenschr 1952;94:1353-60.

2. Levine JD, Goetzl EJ, Basbaum Al. Contribution of the nervous system to the pathophysiology of rheumatoid arthritis and other polyarthritides. Rheum Dis Clin North Am 1987;13:369-83.

3. Härle $\mathbf{P}$, Möbius D, Carr DJ, et al. An opposing time-dependent immune-modulating effect of the sympathetic nervous system conferred by altering the cytokine profile in the local lymph nodes and spleen of mice with type II collagen-induced arthritis. Arthritis Rheum 2005:52:1305-13.

4. Härle $\mathbf{P}$, Pongratz $\mathrm{G}$, Albrecht $\mathrm{J}$, et al. An early sympathetic nervous system influence exacerbates collagen-induced arthritis via CD4+CD25+ cells. Arthritis Rheum 2008;58:2347-55.

5. Straub RH, Grum F, Strauch U, et al. Anti-inflammatory role of sympathetic nerves in chronic intestinal inflammation. Gut 2008;57:911-21.

6. Kin NW, Sanders VM. It takes nerve to tell T and B cells what to do. J Leukoc Biol 2006; 79:1093-104.

7. Watling KJ. The RBI handbook of receptor classification and signal transduction. Natick, Massachusetts, USA: RBI, 1998.

8. Miller LE, Jüsten HP, Schölmerich J, et al. The loss of sympathetic nerve fibers in the synovial tissue of patients with rheumatoid arthritis is accompanied by increased norepinephrine release from synovial macrophages. FASEB J 2000;14:2097-107.

9. Renz H, Gong JH, Schmidt A, et al. Release of tumor necrosis factor-alpha from macrophages. Enhancement and suppression are dose-dependently regulated by prostaglandin E2 and cyclic nucleotides. J Immunol 1988;141:2388-93.
10. Spengler RN, Chensue SW, Giacherio DA, et al. Endogenous norepinephrine regulates tumor necrosis factor-alpha production from macrophages in vitro. $J$ Immunol 1994;152:3024-31.

11. Goldstein RS, Bruchfeld A, Yang L, et al. Cholinergic anti-inflammatory pathway activity and High Mobility Group Box-1 (HMGB1) serum levels in patients with rheumatoid arthritis. Mol Med 2007;13:210-15.

12. van Maanen MA, Lebre MC, van der Poll T, et al. Stimulation of nicotinic acetylcholine receptors attenuates collagen-induced arthritis in mice. Arthritis Rheum 2009;60:114-22.

13. Schaible HG, Grubb BD. Afferent and spinal mechanisms of joint pain. Pain 1993;55:5-54.

14. Heijnen CJ, Rouppe van der Voort C, Wulffraat N, et al. Functional alpha 1-adrenergic receptors on leukocytes of patients with polyarticular juvenile rheumatoid arthritis. $J$ Neuroimmunol 1996;11:223-6.

15. Bergquist J, Tarkowski A, Ekman R, et al. Discovery of endogenous catecholamines in lymphocytes and evidence for catecholamine regulation of lymphocyte function via an autocrine loop. Proc Natl Acad Sci USA 1994;91:12912-16.

16. Musso NR, Brenci S, Setti M, et al. Catecholamine content and in vitro catecholamine synthesis in peripheral human lymphocytes. J Clin Endocrinol Metab 1996;81:3553-7.

17. Cosentino M, Marino F, Bombelli R, et al. Endogenous catecholamine synthesis, metabolism, storage and uptake in human neutrophils. Life Sci 1999;64:975-81.

18. Flierl MA, Rittirsch D, Nadeau BA, et al. Phagocyte-derived catecholamines enhance acute inflammatory injury. Nature 2007;449:721-5.

19. Miller LE, Grifka J, Schölmerich J, et al. Norepinephrine from synovial tyrosine hydroxylase positive cells is a strong indicator of synovial inflammation in rheumatoid arthritis. J Rheumatol 2002;29:427-35.

20. Straub RH, Günzler C, Miller LE, et al. Anti-inflammatory cooperativity of corticosteroids and norepinephrine in rheumatoid arthritis synovial tissue in vivo and in vitro. FASEB J 2002;16:993-1000.

21. Straub RH, Lang B, Falk W, et al. In vitro superfusion method for the investigation of nerve-immune cell interaction in murine spleen. J Neuroimmunol 1995;61:53-60.

22. Straub RH, Schaller T, Miller LE, et al. Neuropeptide $Y$ cotransmission with norepinephrine in the sympathetic nerve-macrophage interplay. J Neurochem 2000;75:2464-71.

23. Cosentino $\mathbf{M}$, Fietta $A M$, Ferrari $M$, et al. Human $C D 4+C D 25+$ regulatory T cells selectively express tyrosine hydroxylase and contain endogenous catecholamines subserving an autocrine/paracrine inhibitory functional loop. Blood 2007; 109:632-42.

24. Lundborg $\mathbf{P}$. Effect of reserpine on the subcellular distribution of $3 \mathrm{H}$-alphamethylnoradrenaline in the mouse heart. Br J Pharmacol 1969;36:386-92.

25. Cosentino $\mathbf{M}$, Zaffaroni M, Marino F, et al. Catecholamine production and tyrosine hydroxylase expression in peripheral blood mononuclear cells from multiple sclerosis patients: effect of cell stimulation and possible relevance for activation-induced apoptosis. J Neuroimmunol 2002;133:233-40.

26. Zaffaroni M, Marino F, Bombelli R, et al. Therapy with interferon-beta modulates endogenous catecholamines in lymphocytes of patients with multiple sclerosis. Exp Neurol 2008;214:315-21. 